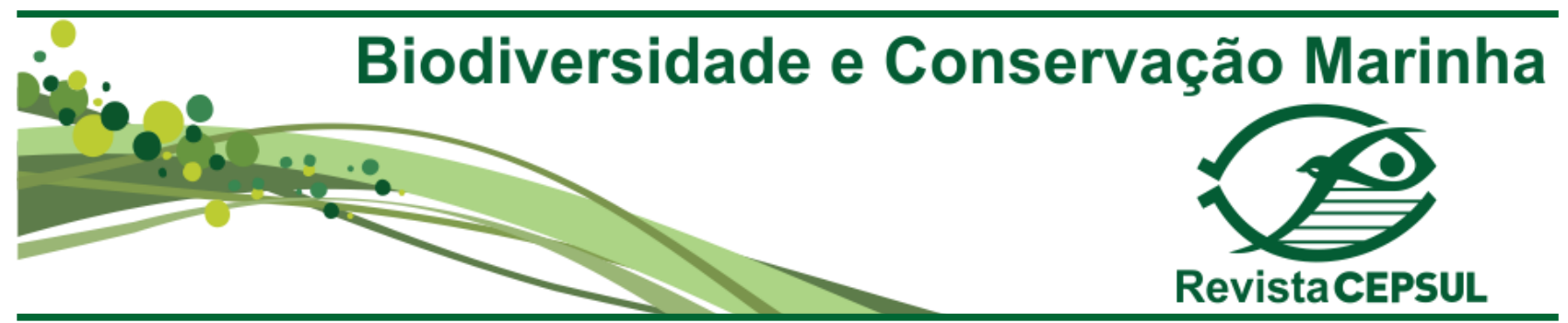

ARTIGO DE REVISÃO - ESPECIAL BABITONGA

\title{
Patrimônio natural das restingas da baía Babitonga, Santa Catarina, Brasil
}

\author{
João Carlos Ferreira de Melo Júnior ${ }^{1}$, Maiara Matilde Silva², Maria Regina Torres \\ Boeger $^{2}$, Thiago Felipe Souza 3 \& Celso Voos Vieira ${ }^{1}$
}

\begin{abstract}
${ }^{1}$ Programa de Pesquisa em Ciências Ambientais, Universidade da Região de Joinville - UNIVILLE, Campus Universitário s/n, Bom Retiro, CEP - 89201-972, Joinville, SC, Brasil ,joao.melo@univille.br; celso.v@univille.br;

${ }^{2}$ Programa de Pós-Graduação em Ecologia e Conservação, Universidade Federal do Paraná - UFPR, Caixa Postal 19031, CEP - 81970 -99o, Curitiba, PR, Brasil, mmatilde.eco@gmail.com; mrtboeger@gmail.com;

${ }_{3}^{3}$ Conservação Marinha do Brasil-Instituto COMAR, Rua Helena Degelmann, 104, Costa e Silva, CEP - 8921858o, Joinville, SC, Brasil, felipeabu@gmail.com.
\end{abstract}

Submetido em: 24/o3/2017; Aceito em: 14/10/2017; Publicado em: 16/10/2018

Resumo. A restinga é um conjunto de comunidades vegetais que ocupam a planície costeira de idade quaternária ao longo da costa brasileira e que, além de se mostrarem frágeis à conservação em função de suas condições ambientais limitantes, apresentam fortes indícios de degradação por ações humanas. Sua diversidade biológica na paisagem ambiental da baía Babitonga ainda não é totalmente conhecida, mas apresenta cerca de 615 espécies de plantas, incluindo endemismos e espécies em risco de extinção. Os resultados dessa investigação, de cunho bibliográfico, indicam a necessidade de aprofundar as pesquisas nas restingas da Babitonga e criar ações e políticas públicas mais efetivas à sua conservação como patrimônio natural coletivo.

Palavras-chave: patrimônio ambiental, paisagem natural, conservação e sustentabilidade, planície costeira, biodiversidade.

\begin{abstract}
Natural heritage of the Babitonga's Bay "restinga", Santa Catarina, Brazil. The "restinga" is a group of vegetal communities that occupy the coastal plain of quaternary age along the Brazilian coast and that, besides being fragile to the conservation due to its limiting environmental conditions, presents strong indications of degradation by human actions. Its biological diversity in the environmental landscape of the Babitonga Bay is not yet fully known, but has 615 species of plants, including endemics and species at risk of extinction. The results of this bibliographic research indicate the need to deepen the research in the "restingas " of Babitonga and to create actions and public policies more effective to its conservation as a collective natural heritage.
\end{abstract}

Keywords: environmental heritage, natural landscape, conservation and sustainability, coastal plain, biodiversity. 


\section{Introdução}

O complexo hídrico da baía Babitonga compreende uma região estuarina localizada ao sul do Brasil, na costa norte do Estado de Santa Catarina ( $26^{\circ} \mathrm{O} 2^{\prime} \mathrm{S}$ e $48^{\circ} 28^{\prime} \mathrm{W}$ ), cuja extensão territorial é de aproximadamente $160 \mathrm{~km}^{2}$ (Kilca et al., 2011) e abrange os municípios de Araquari, Barra do Sul, Garuva, Itapoá, Joinville e São Francisco do Sul (Knie, 2002). É contornada em sua porção noroeste pela Serra do Mar e a sudeste pela ilha de São Francisco do Sul (Cremer, 2006). Abriga em maior proporção as maiores extensões do ecossistema de manguezal do sul do Brasil (Lacerda, 1999), mas possui áreas relictuais de florestas ombrófilas, florestas de transição entre a formação ombrófila e florestas de restinga e pequenas extensões de restinga stricto sensu (Melo Júnior \& Boeger, 2015; Melo Júnior et al., 2017a).

A restinga é classicamente definida como uma formação pioneira de plantas distribuídas em mosaicos nas planícies costeiras ao longo de dunas, cordões, esporões e outras geoformações arenosas originadas por deposição de sedimentos marinhos e secundariamente modeladas por ação do vento (Bigarella, 2001; IBGE, 2012). Esta formação ocorre ao longo de todo o litoral brasileiro, em depósitos quaternários formados por transgressões e regressões marinhas (Araújo \& Henriques, 1984; Veloso et al., 1991) e pertence ao domínio da Mata Atlântica (Rizzini, 1997). Suas comunidades vegetais dependem mais das condições do solo do que do clima e são distribuídas desde a linha da maré alta até as florestas próximas às elevações da Serra do Mar (Rizzini, 1997). Incluem plantas herbáceas, rastejantes e psamófilas, com baixa diversidade em dunas, até árvores de grande porte nas florestas de transição, com maior diversidade vegetal (Melo Júnior \& Boeger, 2015). São consideradas halófitaspsamófitas devido à sua tolerância à salinidade e ao movimento das dunas (Bigarella, 2001). As plantas de restinga são conhecidas por sobreviverem em condições ambientais severas (Fernandes, 2006), caracterizadas pela forte incidência de ventos, alta mobilidade dos sedimentos, elevada salinidade, baixa capacidade de retenção hídrica e deficiência nutricional do solo (Scarano, 2002), condições estas que geralmente variam em gradiente no sentido marcontinente (Melo Jr. \& Boeger, 2015). As formações florestais de restinga encontram-se em porções transicionais para os ambientes de floresta ombrófila e possuem vegetação que mescla componentes florestais de ambas as formações (Melo Jr. \& Boeger, 2015). Os fatores espaciais e temporais das restingas influenciam no desenvolvimento da vegetação e nas características das espécies, demonstrando a existência de padrões estruturais (Pimentel et al., 2007), de convergência adaptativa em atributos funcionais específicos (Boeger \& Gluzezak, 2006; Rosado \& de Mattos, 2007; Chagas et al., 2008; Rosado \& de Mattos, 2010; Bonilha et al., 2013; Melo Júnior \& Boeger, 2016; Melo Júnior \& Boeger, 2017a) e de comunidades com flora e estrutura bem definidas (Melo Júnior \& Boeger, 2015).

Os objetivos deste trabalho foram reunir e apresentar de forma sintética e sistematizada informações sobre a biodiversidade vegetal da restinga associada ao patrimônio ambiental da baía Babitonga, contribuindo com a construção de políticas públicas e ações de conservação dos ecossistemas e da biodiversidade dessa baía e a promoção da qualidade ambiental.

\section{Materiais e métodos}

O presente estudo caracteriza-se como uma pesquisa qualitativa realizada por meio de trabalho de revisão bibliográfica acerca do tema restinga no contexto da baía Babitonga, abrangendo fontes que considerem a abrangência dada pela setorização da área de estudo (Canal do Palmital, Costeira Joinville, Entrada da baía, Ilhas centrais, Linguado-Araquari, Linguado-Barra do Sul, Marinha e Rio Acaraí), conforme descrito por Gerhardinger et al. (2016). Foram utilizadas fontes primárias e secundárias. Foram consideradas fontes primárias informações contidas em bancos de dados de propriedade dos pesquisadores envolvidos na redação deste texto científico, cujos dados tenham sido ou não publicados parcial ou integralmente em veículos de comunicação ci- 
entífica. As fontes primárias foram cedidas pelos Laboratórios de Anatomia e Ecologia Vegetal (Universidade da Região de Joinville) e de Morfologia Funcional (Universidade Federal do Paraná). As fontes secundárias, caracterizadas por trabalhos técnicos e científicos, consideraram publicações em periódicos científicos, livros, relatórios de pesquisa, relatórios técnicos, trabalhos acadêmicos (monografias, dissertações e teses) desde que disponíveis online, documentos jurídicos, imprensa não científica e informações eletrônicas de órgãos e instituições legítimas. A busca pelas fontes secundárias foi realizada por meio de palavras-chave simples ou combinadas por operadores booleanos em bases de dados de acesso livre e restrito, tais como Google Scholar, Portal Capes de Periódicos, Scielo e Web of Science.

\section{Resultados e discussão}

A área coberta por vegetação de restinga é pouco representativa no território abrigado pela baía Babitonga (Figura 1) quando comparada à área ocupada por manguezal, em função das características pedológicas dessa baía que, de forma preponderante, é ocupada por solos indiscriminados de mangue (Knie, 2002). A literatura técnico-científica sobre a composição florística ou a estrutura de comunidades de restinga no contexto da Babitonga ainda é escassa e está representada por um plano de manejo (FATMA, 2008), um relatório de diagnóstico ambiental (Melo Júnior et al., 2008), duas teses de doutorado (Ziffer-Berger, 2008; Melo Júnior, 2015) e quatro artigos (Melo Júnior \& Boeger, 2015; Silva \& Melo Júnior, 2016; Cristofolini et al., 2017; Melo Júnior et al., 2017b). Estudo relacionado aos processos de percepção humana sobre a paisagem da restinga e sua relação com a restauração ambiental compõe uma única monografia (Borges, 2015). Trabalhos que versam sobre a caracterização estrutural e estratégias funcionais de plantas de restinga no ambiente da Babitonga são mais numerosos e estão publicados na forma de artigo (Bachtold \& Melo Júnior, 2015; Todorovski et al., 2015; Liberato \& Melo Júnior, 2016; Melo Júnior \& Boeger, 2016; Silva et al., 2016; Melo Júnior et al., 2016a, 2016b; Amorim \& Melo
Júnior, 2017a; Amorim \& Melo Júnior, 2017b; Melo Júnior \& Boeger, 2017a; Melo Júnior et al., 2017c; Silva \& Melo Júnior, 2017). De acordo com a setorização da baía Babitonga (Gerhardinger et al., 2016), dos 21 estudos citados, 83,33\% correspondem ao setor Marinho, 11,11\% ao setor da Entrada da baía e 5,55\% aos setores Linguado-Araquari e Ilhas Centrais $(2,78 \%$ cada).

A diversidade vegetal é composta por 614 espécies, organizadas em 364 gêneros e 118 famílias botânicas (Tabela 1). Tais espécies estão distribuídas em diferentes ambientes (formações) de restinga, com destaque à restinga herbácea, restinga arbustiva, restinga arbustivo-arbórea e floresta de transição. As espécies estão distribuídas, de forma exclusiva ou compartilhada, em comunidades com fisionomia marcadamente definida, criando formações de restinga com flora e estrutura distintas (Figura 2) (Melo Júnior \& Boeger, 2015).

Conforme padronização dessa vegetação proposta por Melo Júnior \& Boeger (2015) para o ambiente de restinga do Acaraí, melhor caracterizado dentre os ocorrentes na Babitonga, a restinga herbácea é composta por espécies herbáceas e subarbustivas, psammófilas e halófitas, predominantemente rizomatosas, cespitosas e reptantes, crescendo em dunas e antedunas formadas por solo arenoso (Neossolo) com baixa capacidade de retenção de água e nutrientes e baixa fertilidade natural; a restinga arbustiva é formada por densos mosaicos de arbustos de 0,5 a 1,5 m de altura crescendo sobre solo arenoso (Espodossolo) fortemente ácido e de baixa fertilidade; a restinga arbustivoarbórea surge quando as dunas são mais interiores e estáveis, sendo composta por arbustos e árvores entre 2,0 e 5,0 m de altura, habitando solos arenosos (Espodossolos) com formação de camada levemente adensada de serapilheira; e a floresta de transição compõe um estrato contínuo entre 15,0 e 20,0 m de altura formado, predominantemente, por arvoretas e árvores crescendo sobre solo arenoso, mal drenado e rico em matéria orgânica (Espodossolo + Organossolo Hidromórfico), que faz limite com a floresta ombrófila densa de terras baixas ou com áreas de várzea (Figura 2). 


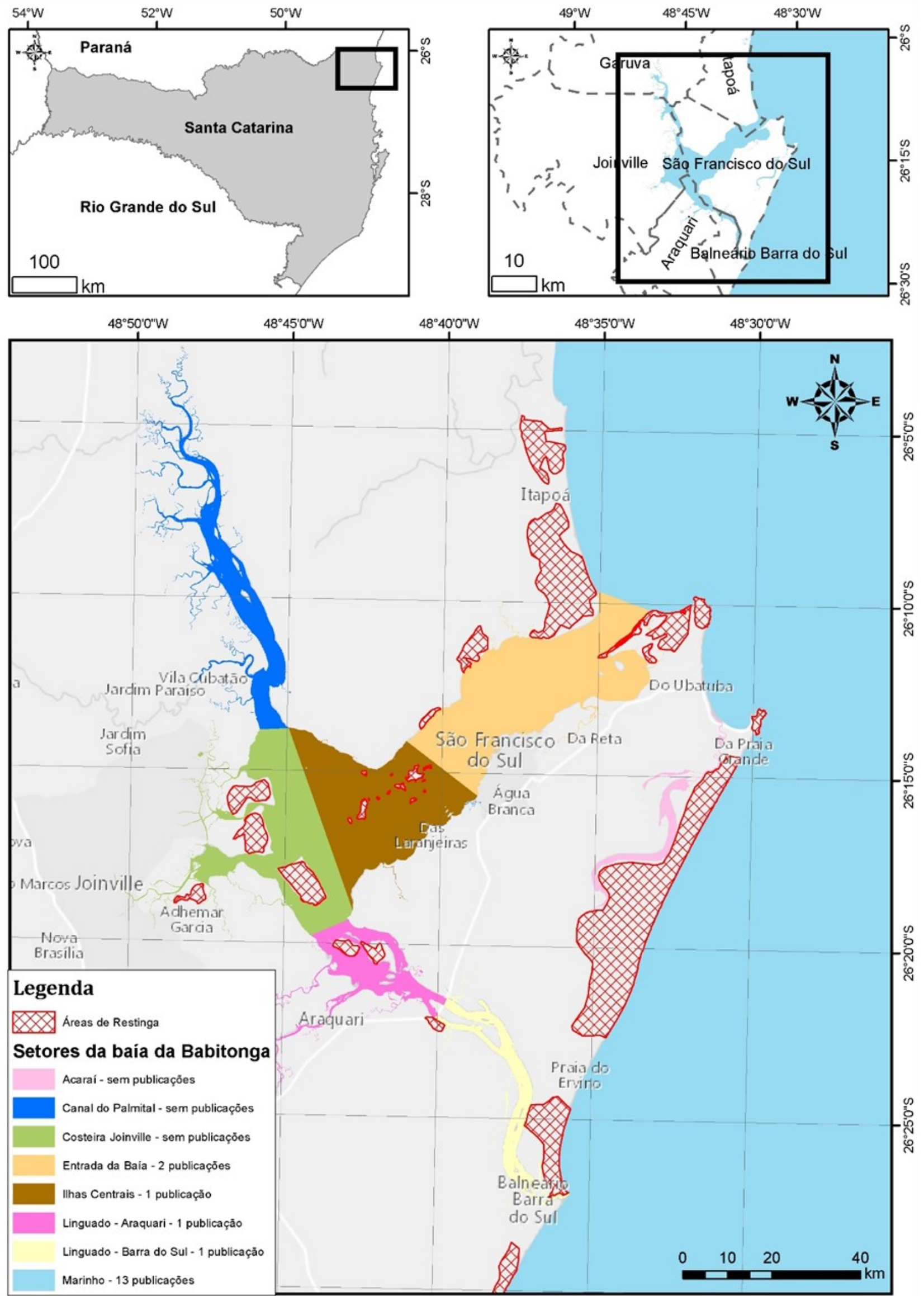

Figura 1. Localização da baía Babitonga, Santa Catarina, Brasil e seus respectivos setores. As porções hachuradas em vermelho indicam as áreas de ocorrência de formações de restinga em seu domínio. Fonte: Gerhardinger et al. (2016). 
Tabela 1. Diversidade de famílias, gêneros e espécies vegetais ocorrentes em comunidades de restinga da baía Babitonga, Santa Catarina, Brasil.

\begin{tabular}{|c|c|c|c|}
\hline Grupo biológico & Família & No de gêneros & No de espécie \\
\hline \multirow{15}{*}{ Pteridófita } & Aspleniaceae & 1 & 2 \\
\hline & Blechnaceae & 1 & 2 \\
\hline & Cyatheaceae & 2 & 2 \\
\hline & Davalliaceae & 1 & 1 \\
\hline & Dennstaedtiaceae & 1 & 2 \\
\hline & Dryopteridaceae & 1 & 1 \\
\hline & Gleicheniaceae & 1 & 1 \\
\hline & Lomariopsidaceae & 1 & 1 \\
\hline & Lycopodiaceae & 2 & 3 \\
\hline & Polypodiaceae & 5 & 10 \\
\hline & Psilotaceae & 1 & 1 \\
\hline & Schizaeaceae & 2 & 2 \\
\hline & Selaginellaceae & 1 & 1 \\
\hline & Thelypteridaceae & 1 & 1 \\
\hline & Vittariaceae & 1 & 1 \\
\hline Gimnosperma & Podocarpaceae & 1 & 1 \\
\hline \multirow{5}{*}{ Angiosperma basal } & Aristolochiaceae & 1 & 3 \\
\hline & Lauraceae & 4 & 9 \\
\hline & Monimiaceae & 1 & 3 \\
\hline & Myristicaceae & 1 & 1 \\
\hline & Piperaceae & 3 & 12 \\
\hline \multirow{18}{*}{ Monocotiledônea } & Amaryllidaceae & 2 & 2 \\
\hline & Araceae & 3 & 11 \\
\hline & Arecaceae & 5 & 8 \\
\hline & Bromeliaceae & 10 & 28 \\
\hline & Cactaceae & 1 & 1 \\
\hline & Cannaceae & 1 & 1 \\
\hline & Commelinaceae & 2 & 4 \\
\hline & Costaceae & 1 & 1 \\
\hline & Cyperaceae & 8 & 13 \\
\hline & Dioscoreaceae & 1 & 1 \\
\hline & Heliconiaceae & 1 & 1 \\
\hline & Iridaceae & 3 & 4 \\
\hline & Juncaceae & 1 & 2 \\
\hline & Maranthaceae & 2 & 3 \\
\hline & Orchidaceae & 27 & 47 \\
\hline & Poaceae & 15 & 22 \\
\hline & Smilacaceae & 1 & 2 \\
\hline & Xyridaceae & 1 & 1 \\
\hline
\end{tabular}


Tabela 1. Continuação.

\begin{tabular}{|c|c|c|c|}
\hline Grupo biológico & Família & No de gêneros & No de espécie \\
\hline \multirow{39}{*}{ Eudicotiledônea } & Acanthaceae & 1 & 1 \\
\hline & Aizoaceae & 1 & 1 \\
\hline & Amaranthaceae & 7 & 10 \\
\hline & Anacardiaceae & 2 & 2 \\
\hline & Annonaceae & 6 & 8 \\
\hline & Apiaceae & 3 & 3 \\
\hline & Apocynaceae & 7 & 7 \\
\hline & Aquifoliaceae & 1 & 4 \\
\hline & Araliaceae & 2 & 2 \\
\hline & Asteraceae & 30 & 56 \\
\hline & Begoniaceae & 1 & 1 \\
\hline & Bignoniaceae & 6 & 7 \\
\hline & Bixaceae & 1 & 1 \\
\hline & Boraginaceae & 1 & 2 \\
\hline & Brassicaceae & 1 & 1 \\
\hline & Cactaceae & 3 & 4 \\
\hline & Calyceraceae & 2 & 3 \\
\hline & Capparaceae & 1 & 1 \\
\hline & Caryophillaceae & 2 & 2 \\
\hline & Celastraceae & 1 & 3 \\
\hline & Chenopodiaceae & 1 & 1 \\
\hline & Chrysobalanaceae & 1 & 1 \\
\hline & Clethraceae & 1 & 1 \\
\hline & Clusiaceae & 4 & 5 \\
\hline & Commelinaceae & 1 & 1 \\
\hline & Convolvulaceae & 3 & 7 \\
\hline & Cunoniaceae & 1 & 1 \\
\hline & Dilleniaceae & 3 & 3 \\
\hline & Elaeocarpaceae & 2 & 3 \\
\hline & Erythroxylaceae & 1 & 5 \\
\hline & Euphorbiaceae & 8 & 11 \\
\hline & Fabaceae & 32 & 50 \\
\hline & Gentianaceae & 1 & 1 \\
\hline & Goodeniaceae & 1 & 1 \\
\hline & Lamiaceae & 1 & 1 \\
\hline & Loganiaceae & 1 & 1 \\
\hline & Loranthaceae & 2 & 2 \\
\hline & Malpighiaceae & 5 & 9 \\
\hline & Malvaceae & 7 & 13 \\
\hline
\end{tabular}


Tabela 1. Continuação.

\begin{tabular}{|c|c|c|c|}
\hline Grupo biológico & Família & No de gêneros & No de espécie \\
\hline \multirow{39}{*}{ Eudicotiledônea } & Marcgraviaceae & 1 & 1 \\
\hline & Melastomataceae & 5 & 16 \\
\hline & Meliaceae & 3 & 4 \\
\hline & Menispermaceae & 1 & 1 \\
\hline & Menyanthaceae & 1 & 1 \\
\hline & Molluginaceae & 1 & 1 \\
\hline & Moraceae & 3 & 10 \\
\hline & Myrtaceae & 13 & 36 \\
\hline & Nyctaginaceae & 1 & 3 \\
\hline & Ochnaceae & 2 & 3 \\
\hline & Olacaceae & 1 & 1 \\
\hline & Onagraceae & 1 & 1 \\
\hline & Orobanchaceae & 1 & 1 \\
\hline & Passifloraceae & 1 & 2 \\
\hline & Pentaphylacaceae & 1 & 1 \\
\hline & Peraceae & 1 & 1 \\
\hline & Phyllantaceae & 2 & 2 \\
\hline & Plantaginaceae & 2 & 2 \\
\hline & Polygalaceae & 1 & 2 \\
\hline & Polygonaceae & 1 & 1 \\
\hline & Portulacaceae & 1 & 1 \\
\hline & Primulaceae & 3 & 9 \\
\hline & Rhamnaceae & 1 & 1 \\
\hline & Rosaceae & 1 & 1 \\
\hline & Rubiaceae & 14 & 26 \\
\hline & Rutaceae & 2 & 2 \\
\hline & Salicaceae & 1 & 1 \\
\hline & Sapindaceae & 6 & 8 \\
\hline & Sapotaceae & 3 & 5 \\
\hline & Simaroubaceae & 1 & 1 \\
\hline & Solanaceae & 1 & 4 \\
\hline & Symplocaceae & 1 & 1 \\
\hline & Theaceae & 1 & 1 \\
\hline & Trigoniaceae & 1 & 1 \\
\hline & Ulmaceae & 1 & 1 \\
\hline & Urticaceae & 3 & 4 \\
\hline & Verbenaceae & 4 & 5 \\
\hline & Vitaceae & 1 & 2 \\
\hline & Winteraceae & 1 & 1 \\
\hline
\end{tabular}


A diversidade de espécies em cada formação também varia conforme a localização do setor na baía Babitonga. Comunidades herbáceas de restinga apresentam considerável variação, sendo registradas oito espécies para o setor das Ilhas Centrais (Ziffer-Berger, 2008), 59 espécies na Entrada da Baía (Ziffer-Berger, 2008; Cristofolini et al., 2017), 77 espécies no setor Marinho do Parque Estadual Acaraí (Melo Júnior \& Boeger, 2015) e 65 espécies no setor Marinho da Barra do Sul (Silva \& Melo Júnior, 2016). A formação arbustiva apresenta riqueza de 76 espécies no setor Marinho do Parque Estadual Acaraí (Melo Júnior \& Boeger, 2015). A formação de restinga arbustivoarbórea tem a flora composta por 110 espécies no setor Marinho do Parque Estadual Acaraí (Melo Júnior \& Boeger, 2015) e 35 espécies no setor Linguado-Araquari (Melo Júnior et al., 2008). Já a floresta é representada por 142 espécies nas Ilhas Centrais e Entrada da Baía (Ziffer-Berger, 2008) e 152 espécies no setor Marinho do Parque Estadual Acaraí (Melo Júnior \& Boeger, 2015). A maior diversidade de espécies ocorre na restinga localizada no Parque Estadual Acaraí (setor Marinho) dada a extensão territorial por ela ocupada (ca. 6,7 mil ha) (Melo Júnior \& Boeger, 2015). Esta área representa, não somente no contexto da baía Babitonga, mas no cenário da região nordeste do Estado de Santa Catarina, o maior e mais importante remanescente de restinga em excelente estado de conservação (PROBIO, 2003), o qual se conecta às restingas da praia do Ervino e formações florestais de restinga e de floresta ombrófila que se estendem até o setor Linguado-Barra do Sul, constituindo uma espécie de corredor de vegetação na Ilha de São Francisco do Sul. Por outro lado, tais áreas não estão inseridas em nenhuma Unidade de Conservação de caráter federal, estadual, municipal ou reserva particular legalmente instituída no estado de Santa Catarina (Martins et al., 2015).

Das 614 espécies registradas nos setores da baía Babitonga, 31 pertencem ao grupo das pteridófitas, uma às gimnospermas e 582 às angiospermas. Dentre as angiospermas, 28 espécies são classificadas como angiospermas basais, 152 monocotiledôneas e 402 eudicotiledôneas (Tabela 1). Para as pteridófitas, as famílias mais ricas são Polypodiaceae (10) e Lycopodiaceae (3). Dentre as angiospermas, as famílias de maior riqueza específica são Asteraceae (56), Fabaceae (50), Orchidaceae (47),

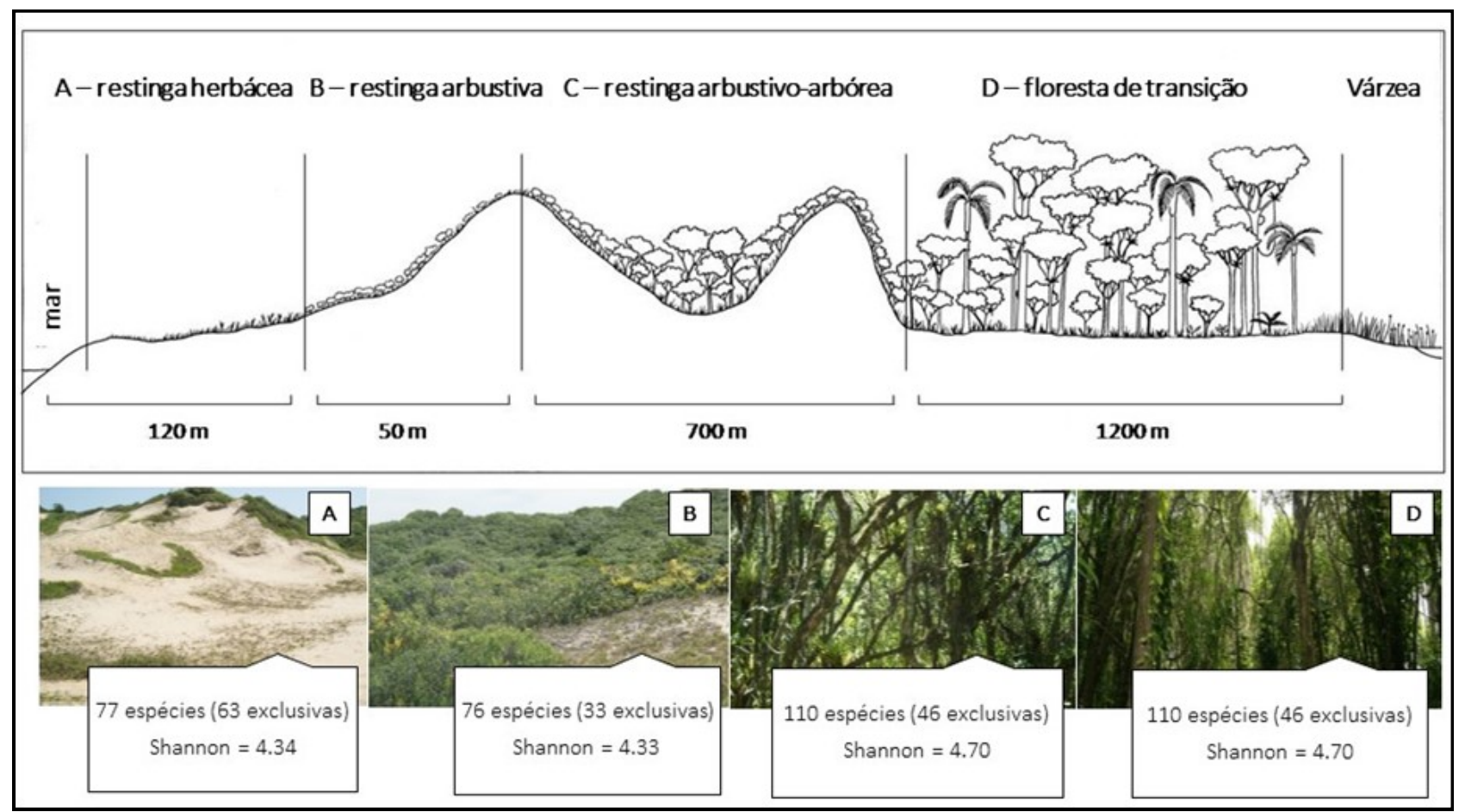

Figura 2. Caracterização geral das principais formações de restinga e diversidade de espécies vegetais associadas ao ambiente da baía Babitonga, Santa Catarina, Brasil. Fonte: primária. 
Myrtaceae (36), Bromeliaceae (28), Rubiaceae (26) e Poaceae (22).

Do ponto de vista estrutural das comunidades de restinga, algumas espécies são, em função de características como grau de cobertura, abundância, densidade e/ou dominância, tidas como indicadoras de fitofisionomias (Cristofolini et al., 2014; Melo Júnior \& Boeger, 2015; Silva \& Melo Júnior, 2016). A tabela 2 mostra as cinco espécies mais características por formação de restinga e o setor da baía Babitonga associado. A figura 3 ilustra as espécies comumente encontradas nas formações de restinga pós-praia na planície costeira do município de São Francisco do Sul.

As formas de vida das espécies estão diretamente associadas às formações de restinga por elas ocupadas e podem sofrer variações intraespecíficas em função das condições ambientais atuantes (Melo Júnior \& Boeger, 2016). O hábito predominante é o herbáceo $(34,20 \%)$, seguido do arbóreo (29,31\%), arbustivo (18,40\%), epifítico (10,58\%), lianescente (7,49\%) e parasita (0,16\%).

Espécies endêmicas e raras, como Heterocondylus reitzii R.M.King \& H.Rob. (Asteraceae), Eugenia brevistyla D.Legrand e Eugenia catharinensis D.Legrand (Myrtaceae), Guapira asperula (Standl.) Lundell (Nyctaginaceae) e Pleurothallis panduripetala Hoehne (Orchidaceae), foram registradas no setor Costeira Joinville/Ilhas Centrais (ZifferBerger, 2008); e endêmica e ameaçada de extinção, como Aechmea pectinata Baker (Bromeliaceae) foi registrada no setor Linguado-Araquari (Melo Júnior et al., 2008).

Os estudos funcionais realizados com populações de espécies indicadoras das formações de restinga tem demonstrado o desenvolvimento de estratégias adaptativas relacionadas às características ligadas ao crescimento e desenvolvimento das plantas mediadas pela influência de filtros ambientais ocasionados pelos fatores ambientais limitantes, geralmente em gradiente, impostos pela restinga. Atributos morfoanatômicos e ecofisiológicos rompem a distância filogenética entre as espécies e criam convergências que as aproximam, maximizan- do os processos de economia de água e alocação de recursos (Bachtold \& Melo Júnior, 2015; Liberato \& Melo Júnior, 2016; Melo Júnior \& Boeger, 2016; Silva et al., 2016; Melo Júnior et al., 2016a, 2016b, Amorim \& Melo Júnior, 2017b; Melo Júnior \& Boeger, 2017a; Melo Júnior et al., 2017c; Silva \& Melo Júnior, 2017).

Além das naturais pressões seletivas que atuam sobre as espécies e tornam as restingas ambientes de extrema fragilidade, conforme Thomazi et al. (2013), são inúmeras as ações humanas associadas ao crescimento das áreas urbanas que provocam a sua progressiva degradação. De forma geral, no estado de Santa Catarina, em função da colonização ter ocorrido a partir da orla marítima, a restinga está entre os ambientes mais degradados (Daniel, 2006). A contínua redução das áreas de restinga decorre, dentre outros fatores, da expansão imobiliária, da ocupação territorial desordenada, da prática turística exploratória, da deposição de lixo sobre a vegetação e do tráfego de veículos sobre as dunas (Rocha et al., 2003). Inserem-se neste cenário, a ocorrência de espécies exóticas com potencial bioinvasor, representadas por 12 espécies distribuídas nos setores Marinho (Melo Júnior \& Boeger, 2015; Silva \& Melo Júnior, 2016), Ilhas Centrais e Entrada da Baía (Ziffer-Berger, 2008). Estudo realizado por Borges (2015), envolvendo a comunidade residente no entorno da restinga, turistas, pescadores e governanças, demonstrou que a função ecológica da restinga é majoritariamente desconhecida e está associada a algo ruim e que traz incômodo às pessoas. Em contrapartida, é sabido pela Ciência que as restingas ocupam papel central na estabilização de ambientes costeiros, bem como, na preservação da flora e fauna residente e migratória. Os remanescentes de restinga ainda existentes devem se tornar fonte de pesquisas científicas que produzam informações aplicáveis ao monitoramento, manejo e restauro da biodiversidade, tal qual a exitosa implantação do módulo de pesquisas ecológicas de longa duração (PELD), localizado na restinga do Parque Estadual Acaraí pelos laboratórios de Anatomia e Ecologia Vegetal e de Ambientes Costeiros da Universidade da Região de Joinville que, 
Tabela 2. Espécies indicadoras das formações de restinga com base nos levantamentos fitossociológicos realizados em diferentes setores da baía Babitonga, Santa Catarina, Brasil. Legenda: PEA (Parque Estadual Acaraí), BBS (Balneário Barra do Sul).

\begin{tabular}{|c|c|c|c|c|}
\hline Setor & Formação & Espécie & Família & Estudo \\
\hline $\begin{array}{l}\text { Entrada da } \\
\text { Baía }\end{array}$ & Herbácea & $\begin{array}{l}\text { Ipomoea pes-caprae (L.) R. Br. } \\
\text { Canavalia rosea }(S w .) D C . \\
\text { Paspalum vaginatum Sw. } \\
\text { Spartina ciliata Brongn. } \\
\text { Vigna sp. }\end{array}$ & $\begin{array}{l}\text { Convolvulaceae } \\
\text { Fabaceae } \\
\text { Poaceae } \\
\text { Poaceae } \\
\text { Fabaceae }\end{array}$ & $\begin{array}{l}\text { Cristofolini et al. } \\
\text { (2014) }\end{array}$ \\
\hline $\begin{array}{l}\text { Linguado- } \\
\text { Araquari }\end{array}$ & $\begin{array}{l}\text { Arbustivo- } \\
\text { Arbórea }\end{array}$ & $\begin{array}{l}\text { Alchornea triplinervia (Spreng.) } \\
\text { Allophylus petiolulatus Radlk. } \\
\text { Amaioua guianensis Aubl. } \\
\text { Annona glabra L. } \\
\text { Bathysa meridionalis L.B.Sm.\& }\end{array}$ & $\begin{array}{l}\text { Euphorbiaceae } \\
\text { Sapindaceae } \\
\text { Rubiaceae } \\
\text { Annonaceae } \\
\text { Rubiaceae }\end{array}$ & $\begin{array}{l}\text { Melo Júnior et al. } \\
\text { (2008) }\end{array}$ \\
\hline \multirow{4}{*}{$\begin{array}{l}\text { Marinho } \\
\text { (PEA) }\end{array}$} & Herbácea & $\begin{array}{l}\text { Smilax campestris Griseb. } \\
\text { Scaevola plumieri (L.) Vahl } \\
\text { Canavalia rosea (Sw.) DC. } \\
\text { Stylosanthes viscosa (L.) Sw. } \\
\text { Blutaparon portulacoides (A.St.- }\end{array}$ & $\begin{array}{l}\text { Smilacaceae } \\
\text { Goodeniaceae } \\
\text { Fabaceae } \\
\text { Fabaceae } \\
\text { Amaranthaceae }\end{array}$ & $\begin{array}{l}\text { Melo Júnior \& Boeger } \\
\text { (2015) }\end{array}$ \\
\hline & Arbustiva & $\begin{array}{l}\text { Guapira opposita (Vell.) Reitz } \\
\text { Myrcia pulchra (O.Berg) Kiaersk. } \\
\text { Norantea brasiliensis Choisy } \\
\text { Clusia criuva Cambess. } \\
\text { Psidium cattleianum Sabine }\end{array}$ & $\begin{array}{l}\text { Nyctaginaceae } \\
\text { Myrtaceae } \\
\text { Marcgraviaceae } \\
\text { Clusiaceae } \\
\text { Myrtaceae }\end{array}$ & $\begin{array}{l}\text { Melo Júnior \& Boeger } \\
\text { (2015) }\end{array}$ \\
\hline & $\begin{array}{l}\text { Arbustivo- } \\
\text { Arbórea }\end{array}$ & $\begin{array}{l}\text { Ocotea pulchella (Nees \& Mart.) Mez } \\
\text { Pera glabrata Poepp. ex Baill. } \\
\text { Ternstroemia brasiliensis Cambess. } \\
\text { Myrsine venosa A.DC. } \\
\text { Ilex theezans Mart. ex Reissek }\end{array}$ & $\begin{array}{l}\text { Lauraceae } \\
\text { Peraceae } \\
\text { Pentaphylacace- } \\
\text { Primulaceae } \\
\text { Aquifoliaceae }\end{array}$ & $\begin{array}{l}\text { Melo Júnior \& Boeger } \\
\text { (2015) }\end{array}$ \\
\hline & $\begin{array}{l}\text { Floresta de } \\
\text { Transiçãoo }\end{array}$ & $\begin{array}{l}\text { Calophyllum brasiliense Cambess. } \\
\text { Alchornea triplinervia (Spreng.) } \\
\text { Nectandra oppositifolia Nees \& } \\
\text { Schinus terebinthifolius Raddi. } \\
\text { Andira fraxinifolia Benth. }\end{array}$ & $\begin{array}{l}\text { Calophyllaceae } \\
\text { Euphorbiaceae } \\
\text { Lauraceae } \\
\text { Anacardiaceae } \\
\text { Fabaceae }\end{array}$ & $\begin{array}{l}\text { Melo Júnior \& Boeger } \\
\text { (2015) }\end{array}$ \\
\hline $\begin{array}{l}\text { Marinho } \\
\text { (BBS) }\end{array}$ & Herbácea & $\begin{array}{l}\text { Panicum racemosum (P. Beauv.) } \\
\text { Hydrocotyle bonariensis Lam. } \\
\text { Ipomoea imperati (Vahl) Griseb. } \\
\text { Remirea marítima Aubl. } \\
\text { Paspalum sp. }\end{array}$ & $\begin{array}{l}\text { Poaceae } \\
\text { Araliaceae } \\
\text { Convolvulaceae } \\
\text { Cyperaceae } \\
\text { Poaceae }\end{array}$ & $\begin{array}{l}\text { Silva \& Melo Júnior } \\
\text { (2016) }\end{array}$ \\
\hline
\end{tabular}

uma vez integrados a Rede Nacional do Programa de Pesquisas em Biodiversidade da Mata Atlântica (PPBio - MA), tem contribuído com a geração de conhecimentos sobre a diversidade biológica da restinga (Melo Júnior \& Boeger, 2017b). 


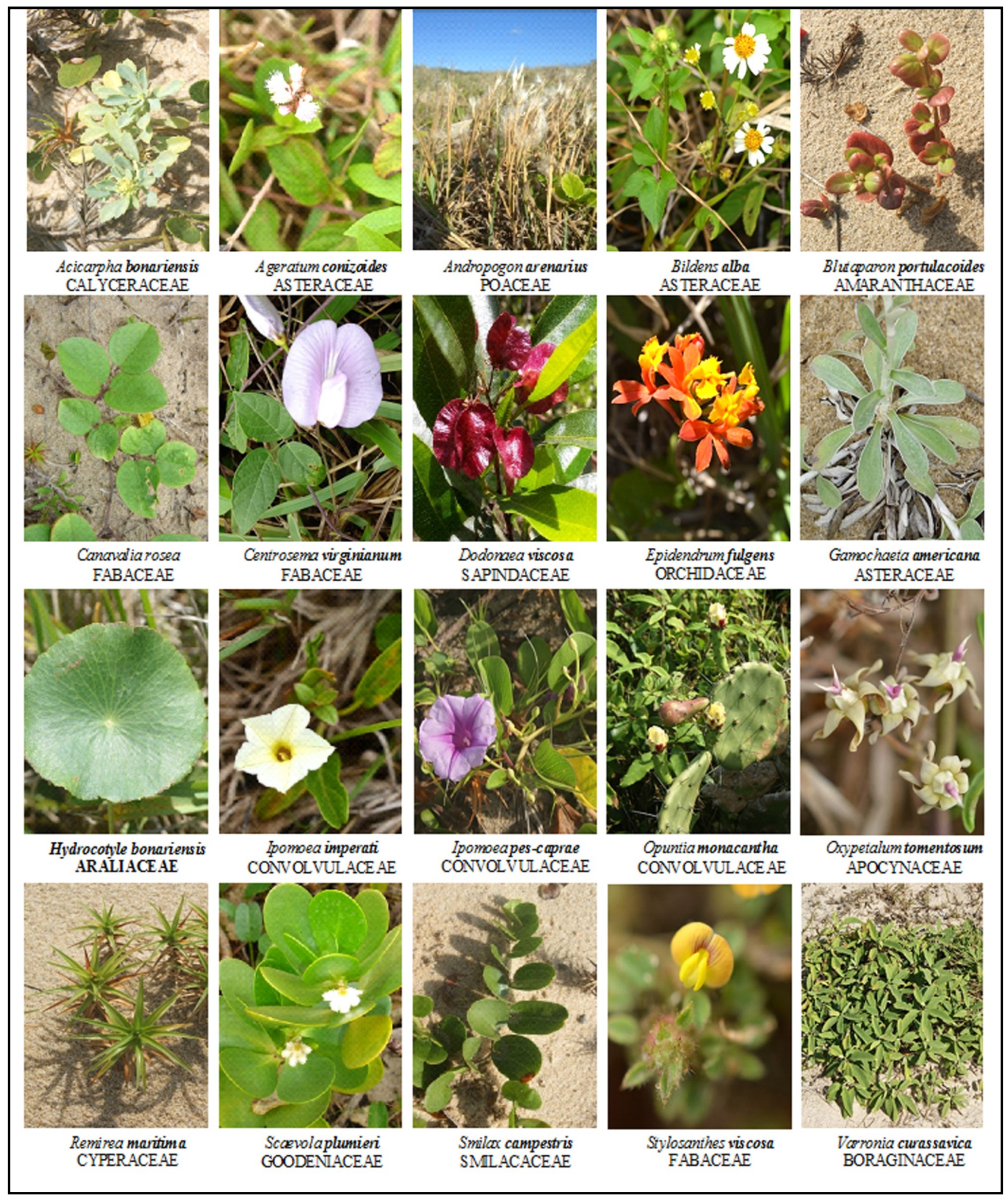

Figura 3. Espécies características das áreas de restinga da baía Babitonga, Santa Catarina, Brasil. Fonte: primária.

Em adição, considerando as interferências do elemento humano na paisagem da restinga, acredita-se que o Ecoturismo, como prática educativa informal e planejada que se sustenta pelos atributos naturais, históricos e culturais peculiares ao local alvo da atividade
(Dines \& Passold, 2008), produza, por meio da integração sociedade-natureza, instrumentos essenciais à conservação da restinga que se desdobrem em mudanças de atitudes e valores humanos (Toledo \& Pelicioni, 2005). Assim, a conservação das áreas relictuais de restinga 
não dependem exclusivamente de um único segmento da sociedade, mas de ações participativas e multissetoriais que deem à restinga o caráter de um patrimônio coletivo e passível de preservação da biodiversidade e dos aspectos culturais e estéticos a ela associados.

\section{Referências Bibliográficas}

AMORIM, M. W. \& MELO JÚNIOR, J. C. F. 2017a. Plasticidade morfoanatômica foliar de Tibouchina clavata (Pers.) Wurdack (Melastomataceae) ocorrente em duas formações de restinga. Rodriguésia, 68(2): 545-555.

AMORIM, M. W. \& MELO JÚNIOR, J. C. F. 2017b. Functional diversity of restinga shrub species on the coastal plain of southern Brazil. Inter. J. Dev. Res, 7(6): 13189-13202.

ARAÚJO, D. S. D. \& HENRIQUES, R. B. 1984. Análise florística das restingas do estado do Rio de Janeiro. In: LACERDA L. D., ARAUJO; R. C, \& TURCQ, B. (ed.). Restingas: origem, estrutura e processos. CEUFF, Niterói, 159-193.

BACHTOLD, B. A. \& MELO JÚNIOR, J. C. F. 2015. Plasticidade morfológica de Calophyllum brasiliense Camb. (Calophyllaceae) em duas formações de restinga no sul do Brasil. $\mathrm{ABC}$, 2(2): 21-32.

BIGARELLA, J. J. 2001. Contribuição ao estudo da planície litorânea do estado do Paraná. Braz. Arch. of Biol. Technol., 1946-2001: 65110.

BOEGER, M. R. T. \& GLUZEZAK, R. M. 2006. Adaptações estruturais de sete espécies de plantas para as condições ambientais da área de dunas de Santa Catarina, Brasil. Iheringia, Sér. Bot., 61(1-2): 73-82.

BONILHA, R. M., CASAGRANDE, J. C., SOARES, M. R. \& REIS-DUARTE, M. 2013. Characterization of the soil fertility and root system of restinga forests. Rev. Bras. Ciênc. Solo, 36: 1.804-1.813.

BORGES, B. 2015. Avaliação da transformação da paisagem litorânea como ferramenta para o restauro ecológico da restinga. Joinville. 38p. (Trabalho de Conclusão de Curso. Departamento de Ciências Biológicas, Univille).
CHAGAS, M. G. S., SILVA, M. D., GALVÍNCIO, J. D. \& PIMENTEL, R. M. M. 2008. Variações foliares em grupos funcionais de uma paisagem de restinga, Pernambuco, Brasil. Ver. Bras. Geo. Fís., 1: 50-63.

CREMER, M. J. 2006. O estuário da Baía da Babitonga. In: CREMER, M. J., MORALES, P. R. D. \& OLIVEIRA, T. M. N. (Org.) Diagnóstico ambiental da baía da Babitonga. Joinville: Univille, 15-19.

CRISTOFOLINI, J., VIEIRA, C. V. \& MELO JÚNIOR, J. C. F. 2017. Relationship between the sand spit geomorphology and Restinga vegetation in São Francisco do Sul island, south region of Brazil. Inter. J. Dev. Res, 7(7): 13314-13321.

DANIEL, R. B. 2006. Florística e fitossociologia da restinga herbácea-arbustiva do Morro dos Conventos, Araranguá - SC. Criciúma. 74p. (Dissertação de Mestrado, Universidade do Extremo Sul Catarinense).

DINES, M. \& PASSOLD, A. J. 2008. Gestão e manejo da recreação em áreas protegidas: do zoneamento à ordenação de trilhas. In: COSTA, N. M C.; NEIMAN, Z. \& COSTA, V. C. (Org). Pelas trilhas do ecoturismo. Rima, São Carlos, Parte III: 169-185.

FATMA - FUNDAÇÃO DO MEIO AMBIENTE. 2008. Plano de manejo do Parque Estadual do Acaraí. Curitiba: FATMA. 232p.

FERNANDES, A. 2006. Fitogeografia brasileira: províncias florísticas. Fortaleza, Realce. 202p.

GERHARDINGER, L. C., FREITAS, R. R., CARVALHO, F. G., HERBST, D. F., MERGEN, B., CUNHA, S., CREMER, M. J., VILA-NOVA, D. \& PFUETZENREUTER, A. 2016. Diagnóstico socioambiental do ecossistema Babitonga. Univille. 168 p.

IBGE. 2012. Manual técnico da vegetação brasileira. 2. ed. IBGE, São Paulo. 271 p.

KILCA, R. V., ALBERTI, L. A., SOUZA, A. M. \& WOLF, L. 2011. Estrutura de uma floresta de mangue na Baía da Babitonga, São Francisco do Sul, SC. CeN. 33(2): 57-72.

KNIE, J. L. W. (org.). 2002. Atlas ambiental da região de Joinville: complexo hídrico da Baía da Babitonga. FATMA/GTZ, Florianópolis. 152p. 
LACERDA L. D. 1999. Os manguezais do Brasil. In: VANNUCCI, M. (Ed.). Os manguezais e nós: uma síntese de percepções. EdUSP, São Paulo: 185-196.

LIBERATO, I. S. \& MELO JÚNIOR, J. C. F. 2016. Morphological plasticity of Ilex theezans Mart. ex Reissek (Aquifoliaceae) in two restinga vegetation of Santa Catarina coastal plain. $\mathrm{ABC}, 3(2)$ : 91-101

MARTINS, L., MARENZI, R. C. \& LIMA, A. 2015. Levantamento e representatividade das Unidades de Conservação instituídas no Estado de Santa Catarina, Brasil. Desenvolv. Meio Ambiente, 33: 241-259.

MELO JÚNIOR., J. C. F. 2015. Plasticidade fenotípica e diversidade funcional de comunidades florísticas em gradiente edáfico na restinga do Parque Estadual do Acaraí, São Francisco do Sul/SC. Curitiba. 168p. (Tese de Doutorado, Departamento de Ciências Biológicas, UFPR).

MELO JÚNIOR., J. C. F., BARTZ, M. C. \& FISHER, T. 2008. Diagnóstico ambiental - Meio biótico - flora BR 280. 67p.

MELO JÚNIOR., J. C. F., AMORIM, M. W. \& ARRIOLA, I. A. 2016a. Anatomia da madeira de Ternstroemia brasiliensis Cambess. (Pentaphylacaceae). Balduinia (UFSM), 55: 17 .

MELO JÚNIOR., J. C. F., AMORIM, M. W. \& ARRIOLA, I. A. 2016b. Anatomia da madeira de Schwartzia brasiliensis (Choisy) Bedell ex Gir.-Cañas (Marcgraviaceae). Balduinia, 55: 8 -16 .

MELO JÚNIOR., J. C. F. \& BOEGER, M. R. T. 2015. Riqueza, estrutura e interações edáficas em um gradiente de restinga do Parque Estadual do Acaraí, Estado de Santa Catarina, Brasil. Hoehnea, 42(2): 207-232.

MELO JÚNIOR., J. C. F. \& BOEGER, M. R. T. 2016. Leaf traits and plastic potential of plant species in a light-edaphic gradient from restinga in southern Brazil. Acta biol. Colomb., 21(1): 51-62.

MELO JÚNIOR., J. C. F. \& BOEGER, M. R. T. 2017a. Functional traits of dominant plant species of the brazilian sandy coastal plain. Int. J. Curr. Res., 9(1): 45585-45593.
MELO JÚNIOR., J. C. F. \& BOEGER, M. R. T. (Orgs.) 2017b. Patrimônio natural, cultura e biodiversidade da restinga do Parque Estadual Acaraí. Joinville: Univille. 478 p.

MELO JÚNIOR, J. C. F., AMORIM, M. W., ARRIOLA, I. A., CANUTO, K. K. \& PEREIRA, L. G. S. 2017a. Florística, estrutura comunitária e conservação de fragmentos da floresta atlântica na bacia hidrográfica do rio Cachoeira, Joinville, SC, Brasil. ABC, 4(3): 8-26.

MELO JÚNIOR, J. C. F., FERRARI, A., GERN, A. F., DANIEL, A., MAIA, A. C., HARTELT, B. T., POSSAMAI, B. T., VANZUITA, C. A., DUMKE, D., SILVA, D., TUSSOLINI, E. G. R., SILVA, G. R., OLIVEIRA, G. B., JANTSCH, G., BATISTA, J. M., FERREIRA, J., BURMESTER, L. P., SANTOS, M. C., SABINO, P. C., VALDEZ, R. E., PINTO, R. F., OLIVEIRA, S. \& SEIFERT-NETO, V. R. 2017b. Fitossociologia comparada da comunidade herbáceo-subarbustiva de restinga em duas geoformações de dunas na planície costeira de Santa Catarina. ABC, 4(2): 5-15.

MELO JÚNIOR., J. C. F., SILVA, M. M., ARRIOLA, I. A., AMORIM, M. W., DIRKSEN, J. S. \& CABRAL, R. D. C. 2017c. Anatomia sistemática e ecológica da madeira de Scaevola plumieri L. (Goodeniaceae). Balduinia, 59: 19.

PIMENTEL, M. C. P., BARROS, M. J., CIRNE, P., MATTOS, E. A., OLIVEIRA, R. C., PEREIRA, M. C. A., SCARANO, F. R., ZALUAR, H. L. T. \& ARAUJO, D. S. D. 2007. Spatial variation in the structure and floristic composition of "restinga" vegetation in southeastern Brazil. Rev. Bras. Bot., 30: 543-551.

PROBIO. 2003. Áreas prioritárias para a conservação, utilização sustentável e repartição de benefícios da biodiversidade brasileira. Brasília, MMA. 301 p.

RIZZINI, C. T. 1997. Tratado de fitogeografia do Brasil. Aspectos ecológicos, sociológicos e florísticos. Âmbito Cultural Edições, Rio de Janeiro, 747 p.

ROCHA, C. F. D., BERGALLO, H. G., ALVES, M. A. S. \& VAN SLUYS, M. 2003. A biodiversidade nos grandes remanescente florestais do estado do Rio de Janeiro e nas restingas da Mata Atlântica. RiMa, São Carlos, 160 p. 
ROSADO, B. H. P. \& DE MATTOS, E. A. 2007. Variação temporal de características morfológicas de folhas em dez espécies do Parque Nacional da Restinga de Jurubatiba, Macaé, RJ, Brasil. Acta Bot. Bras., 21: 741-752.

ROSADO, B. H. P. \& DE MATTOS, E. A. 2010. Interspecific variation of functional traits in a CAM-tree dominated sandy coastal plain. J. Veget. Sci., 21: 43-54.

SCARANO, F. R. 2002. Structure, function and floristic relationships of plant communities in stressful habitats to the brazilian atlantic rainforest. Ann Bot., 90: 517-524.

SILVA, K. R.; MELO JÚNIOR, J. C. F. \& BOEGER, M. R. T. 2016. Variações fenotípicas em Andira fraxinifolia Benth. (Fabaceae) em duas fitofisionomias de Restinga. Hoehnea, 43(2): 237-245.

SILVA, M. M. \& MELO JR. J.C. F. 2016. Composição florística e estrutural de uma comunidade herbáceo-arbustiva de restinga em Balneário Barra do Sul, Santa Catarina. R. Bras. Bioci., 14(4): 207-214.

SILVA, M. M. \& MELO JÚNIOR, J. C. F. 2017. Plasticidade da folha e lenho de cinco espécies em duas áreas de restinga no Sul do Brasil. Iheringia Ser. Bot., 72: 173-180.

THOMAZI, D. R., ROCHA, T. R., OLIVEIRA, V. M., BRUNO, S. S. \& SILVA G. A. 2013. Um panorama da vegetação das restingas do Espírito Santo no contexto do litoral brasileiro. Natureza on line, 11(1): 1-6.

TODOROVSKI, E. D., MELO JÚNIOR, J. C. F., AMORIM, M. W. \& SILVA, M. M. 2015. Potencial plástico de Nectandra oppositifolia Nees (Lauraceae) em fisionomias de floresta omrbófila densa e restinga. Natureza on line, 13: $70-76$.

TOLEDO, R. F. \& PELICIONI, M. C. F. 2005. Educação Ambiental em Unidades de Conservação. In: PHILLIPPI Jr, A. \& PELICIONI, M. C. F. Educação ambiental e sustentabilidade. Malone, Barueri, 749-769p.

VELOSO, H. P., RANGEL-FILHO, A. L. R. \& LIMA, J. C.A. 1991. Classificação da vegetação brasileira, adaptada a um sistema universal. IBGE - DERMA, Rio de Janeiro. 124 p.
Babitonga Bay region (Santa Catarina, Brazil): diversity and origins. 219 p. (Doktorgrades, Naturwissenschaftlichen Fakultät der Universität Erlangen-Nürnberg).

ZIFFER-BERGER, J. 2008. Vascular flora of the 